\title{
Mutation analysis of aryl hydrocarbon receptor interacting protein (AIP) gene in colorectal, breast, and prostate cancers
}

\author{
M Georgitsi', A Karhu', R Winqvist ${ }^{2}$, T Visakorpi ${ }^{3}, K_{\text {Waltering }}{ }^{3}$, P Vahteristo', V Launonen' and \\ LA Aaltonen $*, 1$
}

'Department of Medical Genetics, Molecular and Cancer Biology Research Program, University of Helsinki, 00014 Helsinki, Finland; ' ${ }^{2}$ Departments of Clinical Genetics and Oncology, Oulu University Hospital/University of Oulu, Oulu OYS 90029, Finland; ${ }^{3}$ nstitute of Medical Technology and Tampere University Hospital, University of Tampere, 33014 Tampere, Finland

\begin{abstract}
Germline mutations in the anyl hydrocarbon receptor interacting protein (AIP) gene were recently identified in individuals with pituitary adenoma predisposition (PAP). These patients have prolactin (PRL) or growth hormone (GH) oversecreting pituitary adenomas, the latter exhibiting acromegaly or gigantism. Loss-of-heterozygosity $(\mathrm{LOH})$ analysis revealed that AIP is lost in PAP tumours, suggesting that it acts as a tumour-suppressor gene. Aryl hydrocarbon receptor interacting protein is involved in several pathways, but it is best characterised as a cytoplasmic partner of the aryl hydrocarbon receptor (AHR). To examine the possible role of AIP in the genesis of common cancers, we performed somatic mutation screening in a series of 373 colorectal cancers (CRCs), 82 breast cancers, and 44 prostate tumour samples. A missense RI6H (47G > A) change was identified in two CRC samples, as well as in the respective normal tissues, but was absent in 209 healthy controls. The remaining findings were silent, previously unreported, changes of the coding, noncoding, or untranslated regions of AIP. These results suggest that somatic AIP mutations are not common in CRC, breast, and prostate cancers.
\end{abstract}

British Journal of Cancer (2007) 96, 352-356. doi: I0.1 038/sj.bjc.6603573 www.bjcancer.com (C) 2007 Cancer Research UK

Keywords: pituitary adenoma; PAP; AIP; colorectal tumours; breast tumours; prostate tumours

Germline mutations of aryl hydrocarbon receptor interacting protein $(A I P)$, a gene coding for a cytoplasmic interaction partner of aryl hydrocarbon receptor (AHR) (also known as dioxin receptor), were recently described to cause low-penetrance pituitary adenoma predisposition (PAP) (Vierimaa et al, 2006).

Pituitary adenomas are common benign neoplasms of the anterior pituitary gland and account for approximately $15 \%$ of intracranial tumours. About two-thirds oversecrete pituitary hormones, among which growth hormone $(\mathrm{GH})$ and prolactin (PRL)-oversecreting adenomas are the most common (Heaney and Melmed, 2004). The causal effect of GH oversecretion is acromegaly or gigantism. Cardiovascular, cerebrovascular, respiratory, and metabolic diseases are potential more severe consequences (Melmed et al, 1995; Colao et al, 2004; Jenkins, 2004).

There is accumulating evidence for an increased risk of colorectal cancer (CRC) in acromegaly patients, but also circumstantial evidence that breast and prostate malignancies may arise at a higher risk in the context of acromegaly (Jenkins, 2004). An attractive explanation for the increased risk of CRC in acromegaly has been the link to insulin-like growth factor I (IGF-I). Plasma GH triggers the production of IGF-I from the liver, which in turn stimulates the growth of organs and tissues, through its known mitogenic and

* Correspondence: Professor LA Aaltonen;

E-mail: lauri.aaltonen@helsinki.fi

Received 5 July 2006; revised 30 November 2006; accepted I December 2006 antiapoptotic properties. Any imbalance in the tight control between epithelial cell turn-over and cell death may result in epithelial hyperproliferation, promoting the formation of hyperplastic polyps and colorectal adenomas (Jenkins et al, 2006). Chan et al (1998) have reported a strong positive association between IGF-I levels and increased prostatic malignancy, whereas Peyrat et al (1993) have described increased IGF-I levels in primary breast cancers.

We recently described the PAP phenotype in pituitary adenoma patients from Northern Finland (Vierimaa et al, 2006). Germline AIP mutations segregated with the PAP phenotype in the familial cases, and germline mutations were also identified in sporadic acromegaly patients from Northern Finland. Loss-of-heterozygosity $(\mathrm{LOH})$ analysis revealed loss of wild-type allele in all tumour samples available, suggesting that AIP is likely to act as a tumour suppressor gene.

Aryl hydrocarbon receptor interacting protein is best characterised through its cytoplasmic interaction with the AHR (Carver and Bradfield, 1997), a transcription factor that regulates many xenobiotic metabolising enzymes (Meyer and Perdew, 1999; Marlowe and Puga, 2005). Aryl hydrocarbon receptor interacting protein modulates the stability and subcellular localisation of AHR by preventing its dynamic nucleocytoplasmic shuttling (Pollenz and Dougherty, 2005). Aryl hydrocarbon receptor interacting protein has also been reported to interact with phospho diesterase 4A5 (PDE4A5) (Bolger et al, 2003) and peroxisome proliferatoractivated receptor- $\alpha$ (PPAR- $\alpha$ ) (Sumanasekera et al, 2003).

Many genes involved in hereditary cancer syndromes are also somatically mutated in tumours that are not prominently 
associated with the respective syndromes ( $\mathrm{Li}$ et al, 1997; Avizienyte et al, 1999; Ali et al, 1999; Sanchez-Cespedes et al, 2002). The identification of AIP as a candidate tumour-suppressor gene, lost in both GH and PRL-secreting pituitary adenomas, prompted us to study its possible involvement in other tumour types. According to the global cancer statistics reviewed by Parkin et al for the year 2002 , breast $(18 \%)$, colorectal $(12 \%)$, and prostate cancers $(10 \%)$ are, in terms of prevalence, the most common worldwide (Parkin et al, 2005). To characterise the possible contribution of somatic AIP mutations to the genesis of common cancers, we performed a mutation analysis in a series of CRC, breast, and prostate cancer samples. The inclusion of breast cancer samples was also based on a recent report from Eltom et al (2006), that the levels of nuclear AHR - the cytoplasmic interaction partner of AIP - were dramatically elevated in human breast carcinomas of advanced malignancy compared to earlier stages of tumour progression. In the tumours of advanced malignancy, the nuclear AHR was stabilised and constitutively active.

\section{MATERIALS AND METHODS}

\section{Sample material}

The study was approved by the appropriate ethics review committees. Deoxyribonucleic acid from 52 CRC samples (44 microsatellite stable (MSS) and eight microsatellite unstable (MSI), chosen from a series collected between 1994-1998; Aaltonen et al, 1998; Salovaara et al, 2000) were used for AIP mutation analysis. Aryl hydrocarbon receptor interacting protein exon 1 screening was subsequently extended to $321 \mathrm{CRC}$ samples (272 MSS and 49 MSI) also chosen from the same series collected between 1994 and 1998. The whole set of 373 CRC patients had a mean age at diagnosis of 68 years (range 30-88 years). Colorectal cancer samples were collected as fresh-frozen tissue specimens and displayed at least $50 \%$ tumour tissue, according to pathologist's histological evaluation. Corresponding normal tissue DNA was extracted from blood or normal colonic epithelium, distant from the tumour margins.

A total of 82 breast cancer DNA samples were available for the study. The samples were derived regardless of family history, from patients diagnosed between 1988 and 1994 at the Oulu University Hospital (Winquist et al, 1995). Complete AIP screening was initially performed in 43 samples. Subsequently, AIP exon 6 screening was extended to 39 additional tumour samples. The 82 individuals had a mean age at diagnosis of 54 years (range 29-87 years).

In addition, 44 unselected, genome Phi-amplified (GenomiPhi Amplification kit, Amersham, GE Healthcare, UK), prostate tumour samples from the Tampere region (Waltering et al, 2006) were analysed. Of these, 28 were previously untreated cancers (primary), 12 were hormone-refractory, and four were characterised as benign prostate hyperplasia. The individuals had a mean age at diagnosis of 66 years (range 56-87 years). DNA from 209 anonymous, cancer-free Finnish Red Cross blood donors served as a population-matched control material.

\section{Mutation screening}

The coding region, exon-intron boundaries, as well as the $5^{\prime}$ and $3^{\prime}$ untranslated regions (UTRs) of AIP were PCR-amplified and sequenced as previously described by Vierimaa et al (2006). The potential splicing effect of an intronic change in one breast tumour sample was predicted by computational methods using NetGene2 (http://www.cbs.dtu.dk/services/NetGene2) and the Berkley Drosophila Genome Project (BDGP) (http://www.fruitfly.org/seq_tools/ splice.html) splice site prediction programs. The protein sequences of human AIP and its homologues in other species were obtained from the University of California in Santa Cruz (UCSC) Genome Bioinformatics database, version March 2006 (http://genome.ucsc. edu), and Ensembl Genome Browser, version 38-April 2006 (http:// www.ensembl.org).

\section{RESULTS}

Among the 52 CRC samples initially screened, a heterozygous missense change, $\mathrm{R} 16 \mathrm{H}(47 \mathrm{G}>\mathrm{A})$ in exon 1 was detected in two samples, one being MSS and the other MSI (Table 1). Sequencing of the corresponding normal tissues showed the presence of $\mathrm{R} 16 \mathrm{H}$ in the germline in both cases (Figure 1). The change was absent in 209 healthy controls. The MSS patient had been diagnosed with cancer of the rectum at the age of 64 years. Owing to unilateral breast enlargement, the patient had been examined by nuclear magnetic resonance (NMR) for pituitary adenoma. However, owing to restricted access to medical records in the private sector, and given that this patient is now deceased, no detailed data were available. The MSI patient had been diagnosed with cancer of the colon at the age of 81 years. Her sister had been also diagnosed with CRC at the age of 78 years, and her daughter with cervical cancer at the age of 33 years. Interestingly, her brother had been diagnosed with carcinoid tumour of the rectum at the age of 66 years.

Not knowing whether $\mathrm{R} 16 \mathrm{H}$ is a very rare polymorphism or a pathogenic mutation related to colorectal cancer, we extended the screening of exon 1 to an additional series of 321 CRC samples, but no additional $\mathrm{R} 16 \mathrm{H}$ carriers were observed. In one of these samples, we found a heterozygous G $>$ C change in the $5^{\prime}$ UTR, $5 \mathrm{bp}$ upstream of the start codon (Table 1). This patient had been diagnosed with cancer of the rectum at the age of 72 years. The

Table I AIP changes identified in colorectal, breast, and prostate tumour samples

\begin{tabular}{|c|c|c|c|c|c|c|}
\hline Cancer type & $\begin{array}{l}\text { Number of } \\
\text { patients with } \\
\text { a variant }\end{array}$ & Location & Nucleotide change & $\begin{array}{l}\text { Amino-acid } \\
\text { change }\end{array}$ & $\begin{array}{l}\text { Individuals (allele } \\
\text { frequencies) }\end{array}$ & $\begin{array}{c}\text { Controls (allele } \\
\text { frequencies) }\end{array}$ \\
\hline \multirow[t]{4}{*}{ Colorectal } & 2 & Exon I & $47 G>A$ & $\mathrm{R} 16 \mathrm{H}$ & $2 / 373(0.27 \%)$ & 0/209 \\
\hline & 6 & Exon I & $68 \mathrm{G}>\mathrm{A}$ & G23E & $6 / 373(0.8 \%)$ & $5 / 209(1.2 \%)$ \\
\hline & । & $5^{\prime} \cup T R$ & $-5 G>C$ & - & I/373 (0.13\%) & 0/209 \\
\hline & 2 & $3^{\prime}$ UTR & $+60 \mathrm{G}>\mathrm{C}$ (heterozygous) & - & $2 / 373(0.27 \%)$ & $3 / 182(0.8 \%)$ \\
\hline \multirow[t]{3}{*}{ Breast } & l & Intron 3 & IVS3+I5C>T & - & $1 / 43(1.16 \%)$ & NA \\
\hline & 5 & $3^{\prime} \cup T R$ & +60G >C (heterozygous) & - & & \\
\hline & I & & $+60 \mathrm{G}>\mathrm{C}$ (homozygous) & - & $6 / 81(4.3 \%)$ & $3 / 182(0.8 \%)$ \\
\hline \multirow[t]{2}{*}{ Prostate } & । & Exon I & $36 G>A$ & GI2G & |/44 (I.|4\%) & 0/209 \\
\hline & 1 & Exon 5 & $7 \mid 4 C>T$ & $\mathrm{C} 238 \mathrm{C}$ & $1 / 44(1.14 \%)$ & NA \\
\hline
\end{tabular}

NA $=$ not analysed; UTR $=$ untranslated region. 


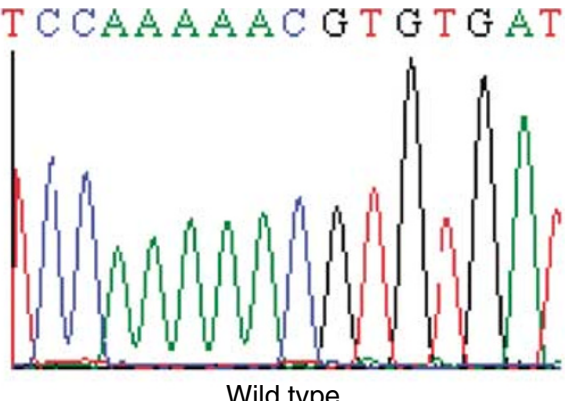

change was present in the patient's germline and absent in 209 healthy controls.

A second heterozygous missense change in exon 1, G23E $(68 \mathrm{G}>\mathrm{A})$, was identified in six out of the total of $373(0.8 \%)$ CRC samples. This change was also observed in five out of 209 healthy controls (1.2\%) (Table 1). Finally, a previously unreported heterozygous $\mathrm{G}>\mathrm{C}$ variant of the $3^{\prime}$ UTR, $60 \mathrm{bp}$ downstream of the termination codon, was identified in two MSI samples out of the total of 373 CRC tumours $(0.3 \%)$. The variant was also observed in three out of $182(0.8 \%)$ healthy controls in heterozygous form.

The screening of breast tumour samples also revealed the $\mathrm{G}>\mathrm{C}$ change in the $3^{\prime}$ UTR, $60 \mathrm{bp}$ downstream of the termination codon. The change was present in six out of $81(4.3 \%)$ breast tumours, of which five were heterozygotes and one was homozygote for the rare $\mathrm{C}$ allele (Table 1$)$. The variant was also observed in three out of $182(0.8 \%)$ healthy controls in heterozygous form $(P=0.026$, Fisher's exact test). In addition, one breast tumour sample had a heterozygous change at IVS $3+15 \mathrm{C}>\mathrm{T}$ (Table 1). This change was not predicted to have a splicing effect, as tested in silico by NetGene2 and BDGP programs.

In prostate tumour samples, the only observed AIP alterations were two previously unreported variants, likely to be silent polymorphisms, in one sample each (Table 1): G12G (36G >A) coding for glycine in exon 1 in a primary cancer sample and C238C $(714 \mathrm{C}>\mathrm{T})$ coding for cystein in exon 5 in a hormone-refractory cancer sample. AIP mutation screening results are summarised in Table 1.

\section{DISCUSSION}

Recently, we reported that $A I P$ is a low-penetrance tumour susceptibility gene, conferring genetic predisposition to pituitary adenomas with high relative, but low absolute, risk (Vierimaa et al, 2006). Little is known concerning the involvement of AIP in pituitary tumorigenesis or progression, as its functional role in that context remains to be clarified. Here, we wished to examine whether AIP is somatically mutated in the most common cancer types: Colorectal, breast, and prostate cancer. No somatic AIP mutations were detected in this study, in accordance with a recent study by Sjöblom et al (2006); AIP was not found to be mutated in human breast and CRC cancer.

The presence of the missense change $\mathrm{R} 16 \mathrm{H}$ in the tumour and corresponding normal tissue (Figure 1) of two CRC patients is an interesting finding. First, the fact that arginine at AIP codon 16 is a highly conserved amino acid among species (Figure 2), second, from the possibility that an occult pituitary adenoma had been present in the MSS patient in which $\mathrm{R} 16 \mathrm{H}$ was identified, one could speculate that such an occult PRL and GH-secreting adenoma may have promoted the breast enlargement, as well as the CRC. Third, the presence of carcinoid tumour in the brother of the MSI R16H-positive patient seems interesting; carcinoids are neuroendocrine tumours, which often occur as part of complex familial endocrine cancer syndromes, such as Multiple Endocrine Neoplasia Type 1 (Leotlela et al, 2003); however, no material was available for segregation studies of the $\mathrm{R} 16 \mathrm{H}$ change in this family. Aryl hydrocarbon receptor interacting protein analyses in additional CRC cases and healthy controls would shed light on this possibility, and clarify whether or not $\mathrm{R} 16 \mathrm{H}$ is associated with neoplasia. We have subsequently encountered the $\mathrm{R} 16 \mathrm{H}$ variant in multiple other individuals with endocrine tumours, but also in one healthy control (unpublished observations). Thus, it is too early to conclude whether this change is pathogenic or not.

We next wanted to examine the possibility that $A I P$ is somatically mutated in unselected breast cancers. Among the breast tumours analysed, we found no pathogenic changes, but only silent, previously unreported, polymorphisms. We presume that the presence of the $3^{\prime}$ UTR $+60 \mathrm{bp} \mathrm{G}>\mathrm{C}$ change in a subset of breast tumour samples, as well as in the two MSI CRC samples, is incidental. The individuals with the variation were somewhat, but not significantly, younger at diagnosis than those without the 


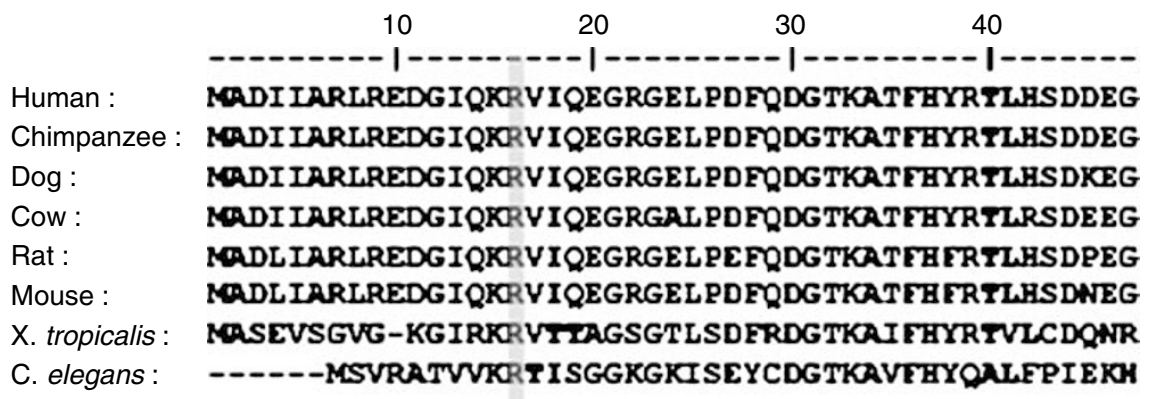

Figure 2 Alignment of human AIP amino-acid sequence and its homologues among species. The conserved arginine (coded by human AIP codon I6) is highlighted by a grey box.

variation $(46 \pm 12.57$ vs $54.82 \pm 13.6$ years; $P \leqslant 0.13$, Student's $t$-test). The clinical data of the six individuals having the $3^{\prime}$ UTR +60 bp G $>$ C change are not uniform: two were familial, one being $B R C A 1$ mutation-positive ( $4216 \mathrm{nt}-2 \mathrm{~A}>\mathrm{G}$ ), and the second being $B R C A 1 / 2$ mutation-negative. All six breast tumours were unilateral; five were infiltrating ductal carcinomas, whereas the familial BRCA1/2 mutation-negative was of medullary type. The malignancy status was also heterogeneous: two were of advanced and two of intermediate malignancy, but no information was available for the remaining two samples. These breast cancer patients originate from the Oulu region of Northern Finland and the $3^{\prime} \mathrm{UTR}+60 \mathrm{bp} \mathrm{G}>\mathrm{C}$ change might represent a variation that is enriched in this population, as it was also observed in three healthy controls. We thus assume that the $3^{\prime} \mathrm{UTR}+60 \mathrm{bp} \mathrm{G}>\mathrm{C}$ change is a previously unreported polymorphism.

No pathogenic changes were identified in the series of prostate tumour samples; two silent variants in $A I P$ exons 1 and 5, respectively, were detected and are likely to be polymorphisms. These findings suggest that AIP mutations are not common in breast and prostate cancers.

Despite the high success rate of AIP DNA amplification (99\%) and the sensitivity of our sequencing analysis system, we might have failed to detect some changes that escape detection by conventional polymerase chain reaction (PCR) and direct genomic sequencing. Such changes might include large genomic rearrangements or promoter methylation, which are common mechanisms for tumour suppressor gene inactivation. On the other hand, our

\section{REFERENCES}

Aaltonen LA, Salovaara R, Kristo P (1998) Incidence of hereditary nonpolyposis colorectal cancer and the feasibility of molecular screening for the disease. $N$ Engl J Med 338: 1481-1487

Ali IU, Schriml LM, Dean M (1999) Mutational spectra of PTEN/MMAC1 gene: a tumor suppressor with lipid phosphatase activity. J Natl Cancer Inst 91: 1922 - 1932

Avizienyte E, Loukola A, Roth S (1999) LKB1 somatic mutations in sporadic tumors. Am J Pathol 154: 677-681

Bolger JB, Peden A, Steele MR (2003) Attenuation of the activity of the cAMP-specific phosphodiesterase PDE4A5 by interaction with the immunophilin XAP2. J Biol Chem 278: 33351-33363, doi:10.1074/ jbc.M303269200

Carver LA, Bradfield CA (1997) Ligand-dependent interaction of the aryl hydrocarbon receptor with a novel immunophilin homolog in vivo. J Biol Chem 272: $11452-11456$

Chan JM, Stampfer MJ, Giovannucci E, Gann PH, Ma J, Wilkinson P, Hennekens CH, Pollak M (1998) Plasma insulin-like growth factor-I and prostate cancer: a prospective study. Science 279: 563 -566, doi: $10.1126 /$ science.279.5350.563

Colao A, Ferone D, Marzullo P, Lombardi G (2004) Systemic complications of acromegaly: epidemiology, pathogenesis, and management. Endocr Rev 25: $102-152$, doi:10.1210/er.2002-0022 results are consistent with the fact that some genes mutated in certain hereditary tumour syndromes are rarely somatically mutated in sporadic tumours. For instance, BRCA1/2 are the two major breast and ovarian cancer susceptibility genes. However, somatic mutations of $B R C A 1 / 2$ in sporadic breast tumours, as well as in other cancer types, are very rare (Futreal et al, 1994; Khoo et al, 1999; Naderi and Couch, 2002; Yang et al, 2002).

The mechanisms by which AIP participates in tumorigenic events in the pituitary are unknown. The present study does not provide strong evidence for immediate involvement of AIP in the initiation or progression of colorectal, breast, and prostate cancer. It remains to be examined whether AIP is somatically mutated in other tumour types more related to pituitary adenomas, such as various neuroendocrine tumours.

\section{ACKNOWLEDGEMENTS}

We thank Sini Marttinen, Inga-Lill Svedberg, and Iina Vuoristo for technical assistance, Pekka Ellonen for sequencing facility and service, and Kari Mononen for help with breast cancer data. This work was supported by the Academy of Finland (Grants 212901, 213183, the Centre of Excellence in Translational Genome-Scale Biology), the Sigrid Jusélius Foundation, the Finnish Cancer Society, the Association for International Cancer Research (Grant 05-001), the Jalmari and Rauha Ahokas Foundation, and the Bodossaki Foundation.
Eltom SE, Gasmelseed AA, Saoudi-Guentri D (2006) The aryl hydrocarbon receptor is over-expressed and constitutively activated in advanced breast carcinoma. Proc Am Assoc Cancer Res 47: 408

Futreal PA, Liu Q, Shattuck-Eidens D, Cochran C (1994) BRCA 1 mutations in primary breast and ovarian carcinomas. Science 266: $120-122$, doi: $10.1126 /$ science.7939630

Heaney AP, Melmed S (2004) Molecular targets in pituitary tumors. Nat Rev Cancer 4: 285 -295, doi:10.1038/nrc1320

Jenkins PJ (2004) Acromegaly and cancer. Horm Res 62(S1): 108 - 115, doi: $10.1159 / 000080768$

Jenkins PJ, Mukherjeet A, Shalet SM (2006) Does growth hormone cause cancer? Clin Endocr 64: 115 - 121, doi:10.1111/j.1365-2265.2005.02404.x

Khoo US, Ozcelik H, Cheung AN (1999) Somatic mutations in the BRCA1 gene in Chinese sporadic breast and ovarian cancer. Oncogene 18: 4643-4646

Leotlela PD, Jauch A, Holtgreve-Grez H, Thakker RV (2003) Genetics of neuroendocrine and carcinoid tumours. Endocr-Relat Cancer 10: $437-450$

Li J, Yen C, Liaw D (1997) PTEN, a putative protein tyrosine phosphatase gene mutated in human brain, breast, and prostate cancer. Science 275: 1943 - 1947, doi: $10.1126 /$ science.275.5308.1943

Marlowe JL, Puga A (2005) Aryl hydrocarbon receptor, cell cycle regulation, toxicity, and tumorigenesis. J Cell Biochem 96: 1174-1184, doi: 10.1002/ jcb.20656 
Melmed S, Ho K, Klibanski A, Reichlin S, Thorner M (1995) Clinical review 75: recent advances in pathogenesis, diagnosis, and management of acromegaly. J Clin Endocr Metab 80: 3395-3402

Meyer BK, Perdew GH (1999) Characterization of the AhR-hsp90-XAP2 core complex and the role of the Immunophilin-related protein XAP2 in AhR stabilization. Biochemistry 38: 8907-8917, doi: 10.1021/bi982223w

Naderi A, Couch FJ (2002) BRCA2 and pancreatic cancer. Int J Gastrointest Cancer 31: 99-106

Parkin DM, Bray F, Ferlay J, Pisani P (2005) Global cancer statistics, 2002. CA Cancer J Clin 55: 74-108

Peyrat JP, Bonneterre J, Hecquet B, Vennin P, Louchez MM, Fournier C, Lefebvre J, Demaille A (1993) Plasma insulin-like growth factor-1 (IGF-1) concentrations in human breast cancer. Eur J Cancer 29A: $492-497$

Pollenz RS, Dougherty EJ (2005) Redefining the role of the endogenous $\mathrm{XAP} 2$ and C-terminal hsp70-interacting protein on the endogenous $\mathrm{Ah}$ receptors expressed in mouse and rat cell lines. J Biol Chem 280: $33346-$ 33356, doi:10.1074/jbc.M506619200

Salovaara R, Loukola A, Kristo P (2000) Population-based molecular detection of hereditary nonpolyposis colorectal cancer. J Clin Oncol 18: $2193-2200$

Sanchez-Cespedes M, Parrella P, Esteller M, Nomoto S, Trink B, Engles JM, Westra WH, Herman JG, Sidransky D (2002) Inactivation of LKB1/STK11 is a common event in adenocarcinomas of the lung. Cancer Res 62: $3659-3662$

Sjöblom T, Jones S, Wood LD (2006) The consensus coding sequences of human breast and colorectal cancers. Science 314: $268-274$, doi: 10.1126/ science. 1133427

Sumanasekera WK, Tien ES, Turpey R, Vanden Heuvel JP, Perdew GH (2003) Evidence that peroxisome proliferator-activated receptor á is complexed with the $90-\mathrm{kDa}$ heat shock protein and the hepatitis virus $\mathrm{B}$ X-associated protein 2. J Biol Chem 278: $4467-4473$, doi:10.1074/jbc. M211261200

Vierimaa O, Georgitsi M, Lehtonen R (2006) Pituitary adenoma predisposition caused by germline mutations in the AIP gene. Science 312: 1228 - 1230, doi: $10.1126 /$ science. 1126100

Waltering KK, Wallén MJ, Tammela TLJ, Vessella RL, Visakorpi T (2006) Mutation screening of the androgen receptor promoter and untranslated regions in prostate cancer. Prostate 66: 1585 - 1591, doi: 10.1002/pros.20387

Winqvist R, Hampton GM, Mannermaa A, Blanco G, Alavaikko M, Kiviniemi H, Taskinen PJ, Evans GA, Wright FA, Newsham I (1995) Loss of heterozygosity for chromosome 11 in primary human breast tumors is associated with poor survival after metastasis. Cancer Res 55: 2660-2664

Yang Q, Yoshimura G, Nakamura M, Nakamura Y, Suzuma T, Umemura T, Mori I, Sakurai T, Kakudo K (2002) BRCA1 in non-inherited breast carcinomas. Oncol Rep 9: 1329-1333 